\title{
O SE-MOVIMENTAR DE ALUNOS NA AULA DE EDUCAÇÃO FÍSICA EM UMA FAVELA CONFLAGRADA PELO TRÁFICO
}

\author{
THE SICH-BEWEGEN OF STUDENTS IN PHYSICAL EDUCATION CLASSES IN A \\ DRUG TRAFFIC-RIDDEN SLUM
}

\author{
EL MOVERSE DE ALUMNOS EN LA CLASE DE EDUCACIÓN FÍSICA EN UNA \\ FAVELA CONFLAGRADA POR EL TRÁFICO DE DROGAS
}

Leonardo Carmo Santos*, Carlos Alberto Figueiredo da Silva *

Palavras chave:

Educação Física.

Violência.

Cultura.

Áreas de pobreza.
Resumo: 0 objetivo deste estudo é interpretar o se-movimentar dos alunos de uma escola pública do Rio de Janeiro, localizada em uma área conflagrada pelo tráfico, de forma a compreender as influências da violência daquela área da cidade no cotidiano das aulas de Educação Física. Foram conduzidas uma observação participante e entrevistas semiestruturadas com professoras de Educação Física. Evidências encontradas durante as observações e ratificadas pelas entrevistas apontam que os alunos usam códigos corporais como um processo de reestabelecimento dos sistemas de autoconfiança social. A repetição dos fenômenos de identificação com o agressor, que se manifestavam no grupo masculino, era ressignificada mantendo-se elementos da cultura de violência, mas introduzindo características das atividades de que participavam.
Keywords:

Physical Education. Violence.

Culture.

Poverty Areas.
Abstract: This study interprets the way of moving of students of a public school located in a drug-traffic-ridden area of Rio de Janeiro to understand the influence of violence in that area of the city in the daily life of Physical Education classes. Participant observation and semi-structured interviews were conducted with Physical Education teachers. Findings indicate that students use bodily codes as a process for reestablishing selfconfidence systems. Repeated identification with their aggressors, which manifested itself in the masculine group, was re-signified while elements of the culture of violence were maintained but introducing characteristics of the activities in which they participated.
Palabras clave: Educación Física. Violencia.

Cultura.

Áreas de pobreza.
Resumen: El objetivo de este estudio es interpretar el Sich-Bewegen de los estudiantes de una escuela pública en Rio de Janeiro, ubicada en un área conflagrada por el tráfico de drogas, para comprender las influencias de la violencia de esa región de la ciudad en el cotidiano de las clases de Educación Física. Se realizaron observación participante y entrevistas semiestructuradas con profesores de Educación Física. Evidencias encontradas durante las observaciones y ratificadas por las entrevistas indican que los estudiantes usan códigos corporales como un proceso de restablecimiento de los sistemas de autoconfianza social. La repetición de los fenómenos de identificación con el agresor, que se manifestaron en el grupo masculino, eran resignificados manteniendo elementos de la cultura de la violencia, pero introduciendo características de las actividades en las que participaban.
*Universidade Salgado de Oliveira. Niterói, RJ, Brasil. E-mail: lleonardosanttos@gmail.com; ca.figueiredo@yahoo.com.br

Recebido em: 20-03-2018 Aprovado em: 12-05-2019 Publicado em: 08-06-2019

DOI: https://doi.org/10.22456/1982-8918.81319 (c) (i) (2) Licence 


\section{INTRODUÇÃO}

Estudo realizado pelo Instituto de Pesquisa Econômica Aplicada (IPEA) demonstra que, a partir de 2013, vários estados tiveram redução no número de homicídios, como, por exemplo: São Paulo (-52,4\%), Rio de Janeiro (-33,3\%), Pernambuco (-27,3\%), Rondônia (-14,1\%), Mato Grosso do Sul $(-7,7 \%)$ e Paraná $(-4,3 \%)$. Entretanto, quando se observam os números de homicídios por intervenções legais em 2014, o Rio de Janeiro foi o estado com o maior número de mortes envolvendo a polícia (IPEA, 2016). Essas mortes deram-se, principalmente, em confrontos da polícia com facções criminosas do tráfico de entorpecentes, e ocorreram em favelas ou próximo a elas.

Tal situação tem afetado diretamente 0 ambiente escolar quando o tráfico se mostra como outra forma de agência socializadora (ZALUAR; LEAL, 2001) que arregimenta jovens vulneráveis para o manejo de armas de fogo - elementos-chave da cultura de rua do tráfico - e acaba arrastando jovens e crianças em idade escolar para a morte prematura (ZALUAR; BARCELLOS, 2013). Bossle, Molina Neto e Wittizorecki (2013) entendem que a cultura de violências intra e extraescolares interfere na qualidade do papel docente, passando pela descentralização do ofício de ensinar para diluí-lo na segurança e custódia dos alunos, o que, mesmo não sendo esse o objeto de estudo dos autores, acaba efetivamente ocorrendo em escolas conflagradas (FERRARI et al., 2017).

Dados do Instituto de Segurança Pública (ISP) aduzem que, entre 2001 e 2011, mais de 10 mil pessoas foram mortas em confrontos com a polícia no Estado do Rio de Janeiro. Nos últimos anos houve um crescimento nesse tipo de homicídio, de acordo com dados do ISP (2018): Capital, em 2014 (247), em 2015 (307) e em 2016 (463); Baixada Fluminense, em 2014 (197), em 2015 (153) e em 2016 (210); Grande Niterói, em 2014 (95), em 2015 (137) e em 2016 (171); Interior do Estado, em 2014 (45), em 2015 (48) e em 2016 (81).

No entanto, segundo Misse (2011, p. 135), esses casos são registrados como "autos de resistência"1 e aponta que os "homicídios registrados sob a rubrica dos "autos de resistência' não são devidamente investigados, havendo uma tendência hegemônica ao arquivamento".

As facções que efetuam o tráfico de entorpecentes estabeleceram suas características com base no domínio de territórios; por estarem nas favelas há mais de trinta anos, arraigaram suas culturas sem sofrer grande resistência (DOWDNEY, 2003). Com isso, a facção dominante se apresenta como "centro de poder na comunidade" (BURGOS et al., 2011, p. 79), mesclandose à multiplicidade cultural das favelas (MEIRELLES, 2014). Os significados desse cotidiano são construídos localmente, a partir da cultura que ali se estabelece, tendo em vista que parte dela, ao mesmo tempo como produto e produtor (CERTEAU, 2013; GEERTZ, 2012; MAUSS, 2013).

As dimensões macrossociais são atualizadas no dia a dia dos sujeitos, e suas experiências subjetivas contribuem para a construção do mundo social, sua mudança, seu dinamismo. A mediação cultural é uma forma para compreender os percursos individuais em meio à diversidade, complexidade e fluidez do urbano (CERTEAU, 2013; SILVA et al., 2015; SIMMEL, 2006; VELHO, 2007). Por exemplo, a construção de brinquedos e de brincadeiras

10 auto de resistência é uma ocorrência registrada na delegacia que descreve uma ação policial contra criminosos, cuja alegação dos policiais é ter havido resistência à prisão e, portanto, a ação empreendida teria sido em legítima defesa. 
que remetem a armas, não apenas nas favelas, mas em todo o Brasil, denota o quão presente está a violência no cotidiano das crianças. Saraiva (2005) acredita que as regras, as maneiras como as crianças jogam e os objetos utilizados por eles são produtos de sua cultura.

Soares et al. (1992) consideram que a técnica não se separa de fatores ideológicos, sociais e psicológicos do indivíduo e da simbologia que o movimento produz na utilização das possibilidades corporais. Assim, o corpo que pertence a uma cultura se expressa, joga ou brinca influenciado por ela (DOWDNEY, 2003; SOARES, 2014).

Porém, se nos colocarmos na posição de observá-los não só na perspectiva de consumidores, mas também como produtores culturais, podemos pensar nessas crianças sob outra ótica. A ampliação do olhar é basilar para pensarmos o mundo da escola nessas áreas conflagradas do Rio de Janeiro.

Diante disso, o presente artigo justifica-se como possibilidade de estimular a discussão com professores de Educação Física e de outras disciplinas sobre o contexto de suas realidades de trabalho, no interior de comunidades com histórico de violência. A realização da presente pesquisa apoia-se em Certeau (2013), quando diz:

\begin{abstract}
A presença e a circulação de uma representação (ensinada como código da promoção socioeconômica por pregadores, por educadores ou por vulgarizadores) não indicam de modo algum o que ela é para seus usuários. É ainda necessário analisar a sua manipulação pelos praticantes que a fabricam. Só então é que se pode apreciar a diferença ou a semelhança entre a produção da imagem e a produção secundária que se esconde nos processos de sua utilização (CERTEAU, 2013, p. 39).
\end{abstract}

Certeau (2013) baseia-se em trabalhos históricos sobre marginalizados culturalmente. Originariamente, uma produção pode ser forçosamente barulhenta e espetacular, mas ao "consumo" corresponde uma a outra produção, astuciosa, dispersa, silenciosa e invisível, não se fazendo notar com produtos próprios, mas em maneiras de empregar os produtos planejados por uma ordem dominante. Essas são formas de reapropriação cultural pelos subalternos (CERTEAU, 2013). A cultura dos conflitos armados confere exibicionismo e maior status social a quem porta armas (ZALUAR; BARCELLOS, 2013), mas pode não significar reprodução descontextualizada nas maneiras de empregar dos alunos, tendo em vista que eles podem manipular essa cultura segundo seus interesses e suas próprias regras.

Pensando nas possíveis relações entre corpo(s) e violência(s), o objetivo principal deste estudo é interpretar o se-movimentar dos alunos e alunas de uma escola pública do município do Rio de Janeiro, localizada em uma área conflagrada pelo tráfico de entorpecentes, de forma a compreender as influências da violência no cotidiano das aulas de Educação Física.

\title{
2 SEGURANÇA ONTOLÓGICA, PODER E SE-MOVIMENTAR
}

Para Kunz (2006, p. 78) "[...] ninguém pode isolar o movimento dos objetos ou do ser que se-movimenta". Desta forma, não são unicamente os movimentos corporais o foco, mas a construção desses movimentos, os temores, as angústias, as alegrias que se entrelaçam no contexto relacional onde ocorrem, revelando e sendo revelado pelo se-movimentar. Nesse sentido, o movimento humano é expressão própria daquele que se-movimenta e não algo mecânico, dissociado de significados (KUNZ, 1991, 2006). 
Com o poder de decisão, e sendo o centro das favelas ocupadas (BURGOS et al., 2011), o tráfico conseguiu exercer atividades e difundir suas culturas atingindo gerações que nasceram entendendo suas leis como o "governo" desses lugares. Tal autoridade se enquadra no que Weber (2011) chama de poder tradicional. Os hábitos e costumes criam certa naturalidade de entendimento das lógicas cotidianas. As pessoas nascem e se criam no ambiente onde a cultura já estava inserida, retransmitindo-a de geração a geração.

Conforme Geertz (2012), somente por ocupar o lugar central do poder, há uma atratividade comum a todos os dominantes históricos, pois comina uma imagem carismática. Os símbolos, histórias, cerimônias e insígnias trabalham a favor da manutenção do domínio.

Nas favelas cariocas, vemos uma realidade semelhante ao que Geertz (2012) e Weber (2011) entendem por mecanismos de manutenção de poder e carisma. O estilo de vida dos traficantes preconiza a ostentação como forma de chamar atenção. Isso exerce fascínio em jovens, especialmente naqueles suscetíveis ao coloquial, no qual as armas e o poder fundamentam as lógicas locais. Zaluar e Barcellos (2013) afirmam que, nesse contexto, os jovens podem buscar o porte de armas de fogo querendo seguir as práticas e valores dessa cultura. Em Ramos (2011), a informação dada como resposta ao questionamento das razões que levavam as armas a possuírem um magnetismo era atrair mulheres, o que pode ser complementado com a ideia de masculinidade que está vinculada a esses grupos (CECCHETTO et al., 2013). Monteiro (2015) e Butelli (2015) colocam o crime como referência positiva para alunos de favelas. Então, portar uma arma na favela representaria uma diferenciação social, uma forma de "ser alguém" lá dentro (RAMOS, 2011).

Nesse contexto cultural, entendemos as diferenças e desafios que uma escola situada em tal ambiente pode enfrentar. A confiança que pessoas adquirem nas trocas sociais, a leitura dos contextos e a compreensão das lógicas locais apoiam a segurança ontológica e esta dará base à autonomia do saber por onde e como andar na favela. Para Giddens (2009):

A vida comum do dia-a-dia - em maior ou menor grau, de acordo com o contexto e os caprichos da personalidade individual - envolve uma segurança ontológica, que expressa uma autonomia do controle corporal no âmbito de rotinas previsíveis (GIDDENS, 2009, p. 58).

Cecchetto et al. (2013) utilizam o termo "segurança ontológica" no sentido de repetição dos fluxos rotineiros, em que pessoas acostumadas a viver ali reconhecem uma continuidade. Silva (2012) diz que, desde criança, aprender a ler os contextos da favela tem um sentido de sobrevivência dos moradores. Então, a interpretação do clima de segurança através da leitura do cotidiano e o entendimento das lógicas locais fundamentam essa competência, garantindo autonomia ao aluno/morador.

A partir da leitura do tecido social local e de seus dominantes, fundamenta-se o que é seguro ser e como agir. Giddens (2009) afirma que a condição para a reprodução de uma estrutura é dependente da compreensão que os agentes têm a respeito do que realizam em seus cotidianos.

No nosso estudo, a estrutura é representada pelas culturas circulantes, e as ações cotidianas demonstram que as reproduções da violência podem estar relacionadas ao reequilíbrio da segurança ontológica (GIDDENS, 2009). O senso de sobrevivência a respeito 
desse comportamento demonstra uma compreensão por parte dos agentes que a reprodução é uma forma econômica de ser entendido. Segundo Giddens:

Ao reproduzirem propriedades estruturais [...] os agentes também reproduzem as condições que tornam possíveis tal ação [...]. Os agentes humanos sempre sabem o que estão fazendo no nível da consciência discursiva, sob alguma forma de descrição (GIDDENS, 2009, p. 31).

Sobre a consciência discursiva, o autor coloca a capacidade que o sujeito tem de expressar suas ações. Quando perguntado sobre o porquê de ter agido daquela forma, todo ator social tem condições de explicar. Da mesma forma, um aluno ou aluna tem a capacidade de responder o porquê de determinada brincadeira. Esta também é uma preocupação da abordagem etnometodológica, não colocando os agentes como "imbecis culturais" (GARFINKEL, 1984), esquadrinhados e achatados pela estrutura, que teria o poder de tirá-los do caminho da consciência de seus atos. Logo, a reflexividade se torna condição para entender a ordem social e suas regras; os agentes as ressignificam, ajustando-as e modificando-as de acordo com suas leituras, interpretações e circunstâncias (SILVA et al., 2015).

Para Kunz (1991, 2006), há intencionalidades nos movimentos. Os sujeitos atribuem sentidos e significados aos seus movimentos, e é no se-movimentar que eles constroem o mundo social. A partir da experiência, o sujeito que se-movimenta sente, percebe e compreende esse "mundo do movimento". Nesse sentido, o corpo em movimento se fia em uma base-referência cujos atributos estão ligados às condições e regras do contexto no qual se está inserido. Assim, este estudo prioriza o se-movimentar do sujeito, o contexto em que o movimento é realizado e os sentidos e significados construídos e relacionados a ele (KUNZ, 2006).

Entendida como identificação por Giddens (2009), essas manifestações estão vinculadas aos processos de confiança, em que essa base-referência parece se alicerçar no "senso de lugar" corporificando a manutenção da segurança ontológica, fornecendo a dialética para "um elo psicológico entre a biografia do indivíduo e os locais que constituem os cenários dos percursos tempo-espaço onde o indivíduo se movimenta" (GIDDENS, 2009, p. 432).

Logo, a ligação com o se-movimentar está atrelada à ideia de que o homem "[...] sempre se movimenta em determinada situação e sob determinadas condições" (KUNZ, 2006, p. 79). Nossa forma de interpretação, em última análise, termina por mostrar uma leitura do contexto e inteligência social presente nas ações práticas dos sujeitos. Não necessariamente isso imputa ao aluno observado o destino de ser um fora da lei. Pode apenas demonstrar que, dentro de sua segurança ontológica (GIDDENS, 2009), ele realizou uma leitura das formas mais bemsucedidas de atingir seus objetivos naquele ambiente e dentro de uma dada situação.

\section{METODOLOGIA}

Esta pesquisa foi desenvolvida ao longo do ano de 2015, sendo utilizada a observação participante em aulas de Educação Física. Concomitantemente, foram realizadas, individualmente, entrevistas semiestruturadas com três professoras de Educação Física, com o objetivo de perceber como estas docentes relatavam as questões da violência em suas aulas. As entrevistas foram gravadas, transcritas e reapresentadas para validação de suas ideias. Às professoras demos os nomes fictícios de Olívia, Yara e Gabriela. Elas tinham, respectivamente, 13 anos de experiência, 2 anos e 8 meses e 7 anos e 4 meses, todas na mesma escola. Como 
critério de escolha das informantes, utilizamos apenas a condição de que tivessem um ano de experiência na escola. O período de observação e entrevistas compreendeu o período de julho a novembro de 2015.

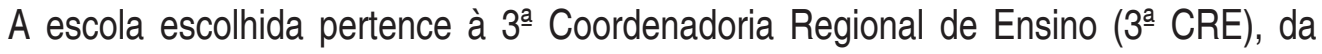
Secretaria Municipal de Educação (SME), cidade do Rio de Janeiro. Esta escola fica localizada no subúrbio, no bairro de Bonsucesso, que se destaca por ser o bairro do estado com maior incidência de violência (RUEDIGER, 2016), no interior do Complexo do Alemão, e foi escolhida por ficar próxima a um dos locais com maior incidência de confrontos armados².

A escola atende à educação infantil (EI) e ao primeiro segmento do ensino fundamental, indo do $1^{\circ}$ ao $5^{\circ}$ ano, com funcionamento nos turnos da manhã e da tarde. Observamos aulas em oito turmas do $1^{\circ}, 2^{\circ}$ e $5^{\circ}$ ano. Nas observações, ficávamos à margem das dinâmicas das aulas e procurávamos ter postura discreta, não intervindo, apesar de a presença do pesquisador no campo suscitar curiosidade nos primeiros dias. Explicávamos nossa presença como professores de EF e que estávamos fazendo um estudo sobre a escola. Pelos alunos, fomos recebidos com abraços carinhosos e alegria ao nos ver: "Tio, você está aqui!" (Aluno). Também éramos percebidos como professores; na ausência das professoras, para irem à toalete, vinham nos pedir autorização para beber água e ir ao banheiro. Foi dessas duas maneiras que nossa identidade transitou pela escola.

Vale ressaltar as dificuldades com as quais nos deparamos para acessar e desenvolver esta pesquisa. Em primeiro lugar, em função dos conflitos armados no Complexo do Alemão, encontramos dificuldade para conseguir autorização da Secretaria de Educação. Contudo, conseguimos o acesso. Em segundo lugar, houve resistência por parte dos atores da escola. Existia um clima de insegurança, e as pessoas evitavam comentar algo que viesse a expô-las posteriormente. Por essa razão, não apresentamos aqui o nome da escola, bem como não identificamos as professoras que colaboraram com a pesquisa.

A abordagem utilizada é qualitativa e se buscou construir as interpretações em conjunto com as professoras entrevistadas. Dessa forma, durante o processo de observação e coleta de dados, diversas vezes recebemos feedback das análises que realizávamos das observações e das falas.

O projeto de pesquisa foi submetido e aprovado pelo comitê de ética em pesquisa, encaminhado via Plataforma Brasil, com o parecer número 1.107.805.

\section{DISCUSSÃO DOS RESULTADOS}

Nesta parte, apresentam-se excertos do diário de campo em conjunto com trechos das falas das professoras entrevistadas. O material original é extenso, não podendo ser apresentado em sua totalidade neste formato. Dessa forma, selecionamos as passagens que nos auxiliaram a entender o objeto de estudo, privilegiando as reflexões focais.

No fragmento a seguir, as professoras falam sobre manifestações "de adesão" a qualquer dos lados, polícia ou bandidos.

Ah, é o falar com muita gíria... é o palavrão, é o 'vou te pegar', é o polícia e ladrão...

é... ah! Imitar. Fazer... fazer... imitar. Imitação de arma... [...] Com o brinquedo,

2 Disponível em: https://extra.globo.com/casos-de-policia/upps-do-rio-registraram-8-mil-tiroteios-em-5-anos-foram-4-confrontos-pordia-23323792.html. Acesso em: 25 mar. 2019. 
com a mão... chacoalhando mesmo: 'Ah! Coé! Coé! Não sei o que... mas, isso também tem muita coisa pro lado de criança também, né! [...] Mas aí é pichação na parede... nome de facção... né? Inicial de facção... 'Não sei o que', é 'UPP é alguma coisa...', né... um palavrão... e aí, assim a gente consegue ver que, que, que tem, sim! Eles chegam aqui já com alguns indícios, já. De... de bandidagem na região, né?! (Professora Gabriela).

A fala da professora expõe as formas de intimidação ou adesão a um comportamento considerado como pertencente aos lados do conflito. A tentativa de falar igual, ameaças e a construção de brinquedos em formato de armas revelam a presença dessa cultura no cotidiano escolar. Como afirma Butelli (2015), jovens na adolescência aderem a comportamentos arriscados como forma de manter um status social. A professora Gabriela também relata que há admiração à polícia, mas em menor grau.

$O$ relato da professora Yara ratifica a fala de Gabriela:

Deve atingir, porque, por exemplo: quando eu dou aqueles... aquelas... bloquinhos. Aqueles negocinhos de montar, a primeira coisa que eles fazem é arma. Entendeu? Então, por eles morarem nessas condições, que é o tempo todo... essa violência, esse bangue-bangue, eu acho que eles... agora, eu não sei se eles querem ser... se... se na fantasia deles, eles são os traficantes ou se eles são os policiais (Professora Yara).

As falas das professoras mostram como é espelhada e reproduzida a situação social dada. Há uma proximidade com o fenômeno, descrito por Giddens (2009), da identificação com o agressor; mas é preciso entender como essas culturas são consumidas (CERTEAU, 2013) e produzidas pelos alunos, pois os sentidos que eles constroem as professoras não conseguem precisar.

Uma sensação de insegurança perpassava as falas das professoras. De certa forma, esse clima afetava diretamente a prática pedagógica. Em estudo realizado em Porto Alegre, Bossle, Molina Neto e Wittizorecki (2013) identificaram nos discursos de professores essa mesma sensação de insegurança e de impotência frente à violência crescente nessa cidade do Sul do Brasil.

Nas observações realizadas, sempre havia crianças brincando com blocos de montar, e nos chamou atenção um fato: se houvesse meninos brincando, em várias oportunidades, era construída alguma arma; se houvesse meninas brincando, isso não ocorria.

Apresentamos alguns excertos do diário de campo para ilustrar a assertiva do parágrafo anterior.

A professora traz o 'lego' e apenas meninas montam. A professora Olívia olha para mim e diz 'Você não vê elas montando armas!' [...] Sobre o que as meninas constroem, ela diz: 'É biscoito, é cozinha, é castelo...' As meninas me mostram umas flores feitas na raquete de badminton. São nove meninas brincando (DIÁRIO DE CAMPO, 15/09/2015, p. 49). [...] Apenas meninas brincaram de 'lego', por muito tempo. Nenhuma arma. Tablets, smartphones e bolos de três andares saíram da montagem de blocos (DIÁRIO DE CAMPO, 03/11/2015, p. 55).

Os objetos projetados nas atividades se diferenciavam entre meninos e meninas. Rotineiramente víamos armas sendo construídas. Eram fuzis, pistolas e espadas, mas não vimos em nenhum dia meninas produzindo qualquer arma. Outras professoras também têm essa percepção. As meninas produzem objetos de consumo como tablets e smartphones, 
bolos, rosquinhas etc.; meninos, além das armas, produzem aviões e robôs, principalmente. Porém, por que vimos armas sendo construídas apenas por meninos?

Encontramos estudos que associam o porte de armas nos contextos de favelas dominadas pelo tráfico no Rio de Janeiro à questão de afirmação da masculinidade (CECCHETTO et al., 2014; RAMOS, 2011; ZALUAR; BARCELLOS, 2013). Para Mauss (2013), a repercussão de uma cultura dada em determinada sociedade se imprime nos movimentos corporais. A maneira pela qual as pessoas utilizam seus corpos revela uma técnica que traz uma singularidade. Mauss acredita que cada sociedade tem seus hábitos próprios, e as técnicas do corpo revelam o simbólico dessas sociedades. O fenômeno da identificação com o agressor revela o simbólico presente no imaginário dos alunos observados nessa escola inserida em uma comunidade conflagrada. A relação entre esses dois conceitos está no se-movimentar dos jovens.

O próximo excerto do diário de campo diz respeito a uma atividade corporal que se refere a uma disputa entre dois grupos mistos. A brincadeira é assim descrita:

\begin{abstract}
Eram os dois grupos, sentados em círculos, cada aluno com um número à sua frente. Um disputando com o outro, a professora chamava por um número, e então os alunos correspondentes a estes números corriam. Quem chegasse primeiro no seu lugar, à equipe correspondente era atribuído o ponto. Um momento de comemoração do ponto conquistado foi 'dramatizado' por um aluno da equipe vitoriosa como se estivesse segurando um fuzil em um dos braços, disparado uma rajada, fazendo com esse braço um movimento para baixo, simulando 0 'coice' que a arma dá quando o tiro é desferido para o alto (DIÁRIO DE CAMPO, 20/10/2015, p. 53).
\end{abstract}

Era notória a alegria do garoto por ter conquistado o ponto para a sua equipe. Acreditamos que esse gesto carrega uma expressão cultural que traz algo de singular (os conflitos) e algo que simboliza essa cultura, materializado na dramatização do corpo, simulando atirar para 0 alto. Em um ambiente onde armas são vistas a todo o tempo e têm sinônimo de poder e virilidade, comemorar assim seria tão estranho?

Ainda que a cena remeta a algo indesejável, é fato que a violência está reificada, um trompe-l'oeil para os olhos que passam superficialmente. Pois o uso cultural (CERTEAU, 2013) presente no movimento expôs que o garoto serviu-se do seu corpo (MAUSS, 2013), passando pelos estágios de realização do gesto, apropriação e inserção em uma rede de relações (entre as culturas e a comunidade escolar), e na localização do tempo escolar, na aula de Educação Física. O gesto reflete os desdobramentos da violência armada, mas também de contentamento, pois, para o garoto, foi uma simples comemoração - um ponto conquistado em um jogo, dentro da escola - sem intencionalidade negativa, haja vista que a expressão do corpo como um todo, e facial, era de alegria.

A especificidade do movimento, carregado de significados, nos remete às técnicas do corpo (MAUSS, 2013); foi dessa forma que o garoto serviu-se dele. O gesto que trazia a marca e a identificação com o agressor foi ressignificado.

Adiante, outros fragmentos do diário de campo, mais direcionados à reprodução das cenas assistidas durante a observação das aulas:

Da turma que ficou (professora Gabriela), um menino constrói com o 'lego' (8h55min) o seu brinquedo em formato de arma. Simula atirar, mas brinca sozinho. Após, pega outra arma maior, parecida com um fuzil. A primeira arma vira uma 
espada, que é colocada nas costas. O fuzil é usado para 'atirar' na direção dos colegas, enquanto anda com a fisionomia fechada, tônus muscular contraído, andando e atirando de costas. Após, cai e permanece 'atirando', tentando. Depois, pega a 'espada' e permanece assim até a professora encerrar a aula às 9h04min. Não sei se era um 'guerreiro' de um desenho ou filme, ou alguém em outra situação. $\mathrm{O}$ que me preocupou foi a fisionomia e a expressão corporal quando estava com duas 'armas' em punho e caminhava atirando de costas (DIÁRIO DE CAMPO, 10/07/2015, p. 3-4). [...] Ainda no queimado, outro aluno, conhecido por ser um dos mais levados, diz 'depois sou eu!'. Poderia ser um simples pedido, mas o semblante fechado e o dedo na cara, com a mão em configuração de arma. (DIÁRIO DE CAMPO, 14/07/2015, p. 10). [...] Voltando da entrega da turma da professora Gabriela, após me despedir e descendo de um andar superior pela escada, um garoto (que me disse ter onze anos, após meu questionamento) estava sentado na escada com um brinquedo articulado que chamou de 'cobra' (parecia uma flauta). la subindo outro garoto pela escada, que foi 'enquadrado' pelo que estava sentado. A 'cobra' virou uma arma, que 'em punho' e apontada para a cabeça do colega, dramatizou uma cena de submissão: 'Para!'. Em seguida: 'Ajoelha!', e a 'arma' continuava acompanhando os movimentos da cabeça do colega, de cima para baixo. A cena foi interrompida pelo inspetor, que disse que não podia ficar na escada, sem fazer nenhuma objeção ao que acabara de presenciar (DIÁRIO DE CAMPO, 17/07/2015, p. 13).

Em todos os trechos, vemos uma reprodução de cenas violentas, mas na repetição e continuidade delas, observamos a aceitação dos envolvidos como uma brincadeira, e parte do ethos de masculinidade (CECCHETTO et al., 2013; RAMOS, 2011; ZALUAR; BARCELLOS, 2013,) expressado no se-movimentar. Entendemos a identificação com o agressor pela leitura sociológica (GIDDENS, 2009) em função dos valores de autoafirmação social (BUTELLI, 2015; CECCHETTO et al., 2013; ZALUAR; BARCELLOS, 2013; RAMOS, 2011) que o contexto e a arma trazem para os jovens do sexo masculino.

Encontramos apoio em Butelli (2015), Cecchetto et al. (2014), Zaluar e Barcellos (2013) e Ramos (2011) para afirmar que esse fenômeno nos parece ser uma tática (CERTEAU, 2013) de autoafirmação perante a comunidade escolar, em que o se-movimentar em conjunto com a linguagem visa à intimidação, identificando-se com o agressor (GIDDENS, 2009), e a forma como os meninos servem-se (MAUSS, 2013) dos seus corpos, espelham-se nas técnicas do corpo (MAUSS, 2013), provindas das culturas do conflito. Desta forma, o corpo é usado como meio para reestabelecer a segurança ontológica (GIDDENS, 2009).

A partir desta análise, falta entender por que vimos a repetição desses fenômenos com tanta frequência. A interpretação que realizamos se apoia no conceito de segurança ontológica mais uma vez. A construção da rotina está diretamente relacionada à autonomia corporal da vida cotidiana. Essa autonomia é construída por meio da 'confiança' que se ganha por meio da repetição dos fatos ao longo do tempo em dado contexto, o que Giddens chama de durée (GIDDENS, 2009).

\section{CONSIDERAÇÕES FINAIS}

O caminho construído nesta pesquisa buscou interpretar o se-movimentar de alunos e alunas durante as aulas de Educação Física. A escola, pública, localiza-se em uma área conflagrada pelo tráfico. Com base nas observações realizadas e no relato de três professoras de Educação Física que atuam na escola, concluímos que os alunos usavam determinados 
códigos corporais como um processo de reestabelecimento dos sistemas de autoconfiança social. A repetição dos fenômenos de identificação com o agressor inscritos nos corpos não trazia 0 entendimento, à primeira vista, de que 0 aluno ao se-movimentar de forma peculiar a uma cultura pertença a ela. Mas que a usa, ressignificando-a, atendendo a seus objetivos últimos de sobrevivência.

Encontramos diferenças de gênero nas formas como o grupo de meninos se movimenta, fala e brinca durante as atividades. Entretanto, nos relatos das professoras entrevistadas, notase um preconceito, cujas percepções são de que os meninos buscam a intimidação. No caso das meninas, o relato das professoras demonstra que as manifestações corporais não utilizam as características apresentadas pelo grupo masculino; não apresentam códigos que remetam à violência e ao conflito. Esses comportamentos são um estilo de masculinidade atrelada ao contexto social marcado pelos conflitos armados, conforme a revisão de literatura realizada neste estudo.

A produção secundária que se esconde nos processos de utilização das imagens via o se-movimentar nos remete às manifestações de similaridade entre o que acontece com os confrontos e o fenômeno da identificação com o agressor. Isto não significa que alguém faça parte do grupo pertencente a alguma facção do tráfico. As formas de brincar e os contextos de uso dos corpos demonstram as leituras sociais dos alunos perante o cotidiano de uma favela conflagrada, onde se expressam tendo em vista suas culturas locais. Essa forma de brincar não pode ser encarada com caráter discriminatório e excludente. As crianças refletem o mundo social que constroem a partir da reflexividade que se oferece no brincar, no lúdico, na teatralização do mundo. 0 que nós, professores, podemos fazer com essa reflexividade? Talvez seja esta a principal missão: que as imagens produzidas pelos corpos não sejam compreendidas somente como reflexo, no sentido de espelhar, mas como um processo criativo de reflexão desses alunos e alunas, que ao se-movimentar buscam possibilidades de estar nesse mundo complexo, injusto e desigual. O questionamento sobre os significados, sentidos e intencionalidades desses movimentos, considerando o contexto sociocultural em que ocorrem, pode auxiliar toda comunidade escolar a problematizar os interesses hegemônicos frente aos significados que são construídos na experiência do movimento por esses alunos.

Nosso posicionamento sobre isso é que são essas, entre outras brincadeiras, as formas encontradas pelos alunos para serem crianças. Semelhante ao relato do garoto que comemora a conquista de um ponto em uma brincadeira é impossível não associar às inúmeras vezes que vemos jogadores de futebol de diversas nacionalidades comemorarem seus gols simulando atirar com "metralhadoras" para as arquibancadas de sua torcida. Este gesto não está dizendo que o jogador quer "atirar" nos torcedores, mas que ele é "matador" (um adjetivo para um goleador) e está comemorando com sua torcida. Acreditamos no contexto social para explicar, em nossa interpretação, os significados, sentidos e intencionalidades corporificadas nas imagens e gestos que "colam" nos traficantes imagens de sucesso. Foi essa a semelhança da técnica do corpo empregada pelo aluno observado. O que marca a diferença em uma criança ver o jogador simular atirar e presenciar in loco alguém próximo dela atirando é a possibilidade real de morte. Por isso, a identificação com o agressor e a reelaboração dessa cena servem para seguir em frente por meio de seu corpo.

As interpretações realizadas neste estudo sugerem o desenvolvimento de um projeto integrador nesta escola, que permita à comunidade (alunos, professores, responsáveis, 
funcionários) a plena reflexão sobre o se-movimentar dos alunos, nas diversas dimensões da aprendizagem, pois o cognitivo não se opõe ao motor e não exclui o psíquico e o sociocultural. Encontramos, principalmente, nas obras de Kunz, Giddens, Mauss e Certeau, que ancoraram as ideias basilares deste trabalho, uma possibilidade de entender o se-movimentar. Mas recorremos a Maine de Biran (1799) neste derradeiro pensamento, pois, para ele, se o indivíduo não quisesse ou não estivesse determinado a se-movimentar, muito pouco conheceria. Se nada lhe resistisse, conheceria menos ainda, não suspeitaria de qualquer existência, nem mesmo teria a ideia de si. O se-movimentar dos alunos não é apenas reprodução; é criação e recriação, uma forma de estar no mundo, interpretá-lo e contribuir com sua construção.

\section{REFERÊNCIAS}

BIRAN, Maine de. Influence de l'habitude sur la faculté de penser. Paris: Presses Universitaires de France, 1799/1954. Disponível em: http://classiques.uqac.ca/classiques/maine de_biran/influence_habitude/influence_\%20habitude.pdf. Acesso em: 26 mar. 2019.

BOSSLE, Fabiano; MOLINA NETO, Vicente; WITTIZORECKI, Elisandro Schultz. Sobre "a vida como ela é": os professores de Educação Física e as violências na escola pública municipal de Porto Alegre. Movimento, v. 19, n. 04, p. 47-67, out./dez. 2013.

BURGOS, Marcelo Baumann et al. O efeito UPP na percepção dos moradores das favelas. Desigualdade \& Diversidade, v. 1, n. 11, p. 49-98, ago./dez. 2011. Disponível em: http:// desigualdadediversidade.soc.puc-rio.br/media/4artigo11.pdf. Acesso em: 28 mar. 2019

BUTELLI, Pedro Henrique. Avaliação do impacto de políticas de segurança: o caso das Unidades de Polícia Pacificadora no Rio de Janeiro. 2015. 200 f. (Doutorado em Economia) Escola de Pós-Graduação, Fundação Getulio Vargas, Rio de Janeiro, 2015.

CECCHETTO, Fátima et al. Os jovens das favelas e a pacificação dos territórios no Rio de Janeiro: estilos e estratégias de convivência com a violência criminal e policial. In: CONGRESO DE LA ASSOCIACIÓN LATINOAMERICANA DE SOCIOLOGÍA, 29, 2013, Santiago. Anais... Santiago: FACSO, 2013. v. 1, p. 1-19.

CERTEAU, Michel de. A invenção do cotidiano 1: artes de fazer. Petrópolis: Vozes, 2013.

DOWDNEY, Luke. Crianças do Tráfico: um estudo de caso de crianças em violência armada organizada no Rio de Janeiro. Rio de Janeiro: 7 letras, 2003.

FERRARI, Carlos Eduardo; SILVA, Carlos Alberto Figueiredo; SANTOS, Roberto Ferreira; MOTTA, Jorge França; FARIA JUNIOR, Alfredo Gomes. The influence of violence in physical education classes in Rio de Janeiro favelas. Espacios, v. 38, n. 60, p. 14, 2017.

GARFINKEL, Harold. Studies in ethnomethodology. Cambridge: Polity Press, 1984.

GEERTZ, Clifford. O saber local: novos ensaios em antropologia interpretativa. Petrópolis: Vozes, 2012.

GIDDENS, Anthony. A constituição da sociedade. São Paulo: WMF Martins Fontes, 2009. 
IPEA . INSTITUTO DE PESQUISA ECONÔMICA APLICADA. Atlas da violência 2016. Disponível em: http://infogbucket.s3.amazonaws.com/arquivos/2016/03/22/atlas da violencia 2016.pdf. Acesso em: 06 fev. 2018.

ISP. INSTITUTO DE SEGURANÇA PÚBLICA Dados abertos. Disponível em: http://www. ispvisualizacao.ri.gov.br/Letalidade.html. Acesso em: 21 fev. 2018.

KUNZ, Elenor. Educação física: ensino \& mudança. ljuí: Unijuí, 1991.

KUNZ, Elenor. Transformação didático-pedagógica do esporte. ljuí: Unijuí, 2006.

MAUSS, Marcel. Sociologia e antropologia. São Paulo: Cosac Naify, 2013.

MEIRELLES, Renato. Um país chamado favela: a maior pesquisa já feita sobre a favela brasileira. São Paulo: Gente, 2014.

MISSE, Michel. "Autos de resistência": uma análise dos homicídios cometidos por policiais na cidade do Rio de Janeiro (2001-2011). Núcleo de Estudos da Cidadania, Conflito e Violência Urbana, Universidade Federal do Rio de Janeiro. Edital MCT/CNPq No 14/2009 - Universal, 2011. Disponível em: http://www.pm.es.gov.br/download/policiainterativa/PesquisaAutoResistencia. pdf. Acesso em: 07 fev. 2018.

MONTEIRO, Ane. A prática pedagógica no cotidiano de uma escola da favela. Jundiaí: Paco, 2015.

RAMOS, Silvia. Trajetórias no tráfico: jovens e violência armada em favelas cariocas. Trivium: estudos interdisciplinares, Rio de Janeiro, v. 5, n. 2, p. 41-57, jul/dez. 2011.

RUEDIGER, Marco Aurélio. Denúncia, crime e castigo: o ciclo da violência na cidade do Rio de Janeiro. 2016. Disponível em http://dapp.fgv.br/denuncia-crime-e-castigo-o-ciclo-de-violencia-nacidade-rio-de-janeirol. Acesso em 25 mar. 2019.

SARAIVA, Maria do Carmo. Co-educação física e esportes: quando a diferença é mito. ljuí: Unijuí, 2005.

SILVA, Carlos Alberto Figueiredo da et al. A contribuição da etnometodologia para os estudos sociológicos na Educação Física brasileira. Movimento, v. 21, n. 1, p. 233-248, jan./mar. 2015.

SILVA, Rodrigo Torquato da. Escola-favela e favela-escola: "esse menino não tem jeito!". Petrópolis: DP et Alii, 2012.

SIMMEL, Georg. Questões fundamentais de sociologia: indivíduo e sociedade. Rio de Janeiro: Zahar, 2006.

SOARES, Carmem Lúcia et al. Metodologia do ensino da educação física. São Paulo: Cortez, 1992.

SOARES, Luiz Eduardo. Prefácio. In: MEIRELLES, Renato. Um país chamado favela: a maior pesquisa já feita sobre a favela brasileira. São Paulo: Gente, 2014. p. 7-16.

VELHO, Gilberto (org.). Rio de Janeiro: cultura, política e conflito. Rio de Janeiro: Jorge Zahar, 2007.

WEBER, Max. Ciência e política: duas vocações. São Paulo: Cultrix, 2011. 
ZALUAR, Alba; LEAL, Maria Cristina. Violência extra e intramuros. Revista Brasileira de Ciências Sociais, v. 16, n. 45, p. 145-164, fev. 2001

ZALUAR, Alba; BARCELLOS, Christovam. Mortes prematuras e conflito armado nas favelas do Rio de Janeiro. Revista Brasileira de Ciências Sociais, v. 28, n. 81, p. 17-31, fev. 2013.

\section{Apoio:}

Universidade Salgado de Oliveira, RJ, Brasil. 